\title{
Cortical and trabecular bone mineral density in transsexuals after long-term cross-sex hormonal treatment: a cross-sectional study
}

\author{
Adrian G. Ruetsche · Renato Kneubuehl \\ Martin H. Birkhaeuser · Kurt Lippuner
}

Received: 31 October 2003 / Accepted: 24 August 2004 / Published online: 16 October 2004

(C) International Osteoporosis Foundation and National Osteoporosis Foundation 2004

\begin{abstract}
The aim of this study was to explore the effect of long-term cross-sex hormonal treatment on cortical and trabecular bone mineral density and main biochemical parameters of bone metabolism in transsexuals. Twenty-four male-to-female (M-F) transsexuals and 15 female-to-male (F-M) transsexuals treated with either an antiandrogen in combination with an estrogen or parenteral testosterone were included in this cross-sectional study. BMD was measured by DXA at distal tibial diaphysis (TDIA) and epiphysis (TEPI), lumbar spine (LS), total hip (HIP) and subregions, and whole body (WB) and $Z$-scores determined for both the genetic and the phenotypic gender. Biochemical parameters of bone turnover, insulin-like growth factor-1 (IGF-1) and sex hormone levels were measured in all patients. M-F transsexuals were significantly older, taller and heavier than F-M transsexuals. They were treated by cross-sex hormones during a median of 12.5 years before inclusion. As compared with female age-matched controls, they showed a significantly higher median $Z$-score at TDIA and WB $(1.7 \pm 1.0$ and $1.8 \pm 1.1, P<0.01)$ only. Based on the WHO definition, five (who did not comply with cross-sex hormone therapy) had osteoporosis. F-M transsexuals were treated by cross-sex hormones during a median of 7.6 years. They had significantly higher median $Z$-scores at TEPI, TDIA and WB compared with female age-matched controls $(+0.9 \pm 0.2 \mathrm{SD}$, $+1.0 \pm 0.4 \mathrm{SD}$ and $+1.4 \pm 0.3 \mathrm{SD}$, respectively, $P<$ 0.0001 for all) and reached normal male levels except at TEPI. They had significantly higher testosterone and
\end{abstract}

A. G. Ruetsche $\cdot$ R. Kneubuehl $\cdot$ K. Lippuner $(\varangle)$

Osteoporosis Unit, University Hospital of Berne,

CH-3010 Berne, Switzerland

E-mail: kurt.lippuner@insel.ch

Tel.: + 41-31-6323128

Fax: +41-31-6329596

Department of Gynecological Endocrinology

and Reproductive Medicine,

University Hospital of Berne,

Berne, Switzerland
IGF-1 levels $(p<0.001)$ than M-F transsexuals. We conclude that in M-F transsexuals, BMD is preserved over a median of 12.5 years under antiandrogen and estrogen combination therapy, while in F-M transsexuals BMD is preserved or, at sites rich in cortical bone, is increased to normal male levels under a median of 7.6 years of androgen treatment in this cross sectional study. IGF-1 could play a role in the mediation of the effect of androgens on bone in F-M transsexuals.

Keywords Bone mineral density (BMD) - DXA · IGF-1 $\cdot$ Transsexuals

\section{Introduction}

Estrogens and androgens play important roles in skeletal growth and in the maintenance of the adult bone mass [1]. Sex hormone deficiency represents a major cause of osteoporosis in both genders [2,3] and substitution of sex steroids preserves or even increases bone mass in men and women [4,5]. For obvious reasons, hormone substitution is usually based on the use of sex-matched hormones $[6,7,8,9]$. Although there is increasing evidence that cross-sex hormones, as physiologically produced in smaller amounts in both genders, do play a certain role in the maintenance of skeletal homeostasis [10], it is unclear whether in adults, cross-gender hormone treatment may fully compensate for the lack of genotypic gonadal hormones with respect to bone health.

The diagnosis of "transsexualism", although explicitly classified in DSM-III-R (Diagnostic and Statistical Manual of Mental Disorders), has been replaced by "gender identity disorder" in the DSM-IV. However, transsexualism is included in the 10th revision of the International Classification of Diseases (ICD-10) and persons affected by this disorder refer to themselves as transsexuals. Under these premises, this publication uses the word transsexualism, referring to the gender identity disorder. Transsexualism is a condition in which the medical management of cross-sex reassignment is initi- 
ated and maintained using estrogen and antiandrogen treatment in male-to-female (M-F) and androgen treatment in female-to-male (F-M) transsexuals. Only a very few studies have addressed the question whether BMD in transsexuals is preserved while under cross-sex hormonal therapy and their results are rather conflicting $[11,12,13,14,15]$. The only data on bone health in Caucasian transsexuals have been published by a Dutch group $[12,13,14,15,16]$. One remaining report in the world literature comes from Asia, investigating Singaporean F-M transsexuals [11].

Using histomorphometry from transiliac bone biopsies, Lips et al. observed a suppression of bone turnover and a preservation of bone mass in both, M-F [12], and F-M [13] transsexuals. Median duration on cross-sex hormone treatment was 24 months in the former and 39 months in the latter study. Whereas mean bone mineral density (BMD) of the lumbar spine remained unchanged in F-M transsexuals, it increased slightly in M-F transsexuals during 1 year of cross-gender hormone treatment [14]. However, follow-up measurements in subsamples of the above populations showed less favorable results: whereas lumbar BMD was maintained in the $20 \mathrm{M}-\mathrm{F}$ transsexuals after $32-63$ months of crosssex hormone treatment, the 19 F-M transsexuals experienced significant decreases in their lumbar BMD while under androgen treatment for 28-53 months [15]. The results of the Singaporean study are difficult to interpret, due to the short observation time, inhomogeneity with respect to gonadectomy, unknown compliance with hormone treatment and additional treatment using calcium [11].

Although estrogen receptors and androgen receptors are present in osteoblasts of both sexes, cortical bone contains more androgen receptors than trabecular bone $[17,18,19]$, which provides a possible explanation for the higher cortical bone mass observed in normal men compared with women [4]. In addition, it has been shown that the effects of androgens compared with those of estrogens are similar on trabecular bone but opposite on cortical bone of males [20]. Therefore, it is possible that switching to cross-gender hormones during adult age leads to differential changes in bone density depending on the skeletal site studied, i.e. cortical or trabecular.

The aim of this cross-sectional study was to explore the effect of long-term cross-sex hormonal treatment on cortical and trabecular bone mineral density and main biochemical parameters of bone metabolism in transsexuals.

\section{Materials and methods}

Subjects and sex hormone treatment

Twenty-four M-F transsexuals and 15 F-M transsexuals, who were controlled regularly in the Outpatient Department of Gynecologic Endocrinology and Repro- ductive Medicine of the University Hospital of Berne between 1973 and 2000 and who showed normal hormone status and phenotype according to their genetic sex prior to cross-sex hormone treatment participated to this cross-sectional study (Table 1). All participants gave their prior written informed consent and the study was approved by the Hospital Ethical Review Board.

\section{M-F transsexuals}

Before surgery, sex reassignment had been initiated with a fixed combination of an antiandrogen with a synthetic estrogen (cyproterone acetate $2 \mathrm{mg}$ /day and ethinyl estradiol $35 \mu \mathrm{g} /$ day; Diane 35, Schering AG, Germany) or a free combination of the same compounds [cyproterone acetate $2 \mathrm{mg} /$ day (Androcur) and ethinyl estradiol 35-100 $\mu \mathrm{g}$ /day (Progynon C or Lynoral, Schering AG, Germany)]. Surgery consisted of different reconstruction techniques, the choice being dependent on general health, physical, anatomical and psychological characteristics of the individual patient. All patients underwent orchidectomy, eventually followed by penisectomy and vaginoplasty usually in combination with clitoroplasty and implantation of breast implants. After surgery, cross-sex hormone treatment was continued using estradiol valerate (Progynova; Schering AG, Germany) or micronized 17-beta estradiol (Estrofem; Novo Nordisk) $2-4 \mathrm{mg} /$ day.

\section{F-M transsexuals}

Sex reassignment had been initiated with parenteral testosterone esters (Testoviron Depot; Schering AG) $250 \mathrm{mg}$ every 3 weeks IM before surgery, which was continued at the same posology after surgery. Surgery consisted of hysterectomy, ovariectomy and bilateral mastectomy in all patients, while surgical penis reconstruction was inconsistently reported.

Table 1 Clinical characteristics of 24 male-to-female $(M-F)$ and 15 female-to-male $(F-M)$ transsexuals. Results given as median \pm MAD (range). BMI body mass index, $M A D$ median absolute deviation

\begin{tabular}{lll}
\hline & \multicolumn{2}{l}{ Transsexuals } \\
\cline { 2 - 3 } & M-F & F-M \\
\hline Age, years & $44.4 \pm 7.7(29.8-67.9)$ & $34.4 \pm 5.6(25.6-53.3)^{*}$ \\
Age at & $30.0 \pm 6.0(21.1-62.5)$ & $23.5 \pm 3.5(18.1-37.1)$ \\
surgery, years & \\
Height, cm & $174.5 \pm 3.5(162.0-182.0)$ & $166.0 \pm 3.0(149.0-172.0)^{*}$ \\
Weight, kg & $77.2 \pm 12.2(50.0-115.0)$ & $60.2 \pm 8.0(49.0-78.5)^{*}$ \\
BMI, kg/m & $25.6 \pm 3.4(15.4-37.1)$ & $25.0 \pm 2.6(20.9-27.6)$ \\
Treatment, years & \\
Pre-surgery & $2.1 \pm 0.7(0.7-8.7)$ & $1.3 \pm 0.3(0.5-3.7)^{*}$ \\
Post-surgery & $9.7 \pm 4.6(1.0-24.0)$ & $6.1 \pm 3.4(1.8-22.9)$ \\
Total & $12.5 \pm 4.7(4.7-24.7)$ & $7.6 \pm 3.8(2.8-24.0)$ \\
\hline
\end{tabular}

$* P<0.01 \mathrm{~F}-\mathrm{M}$ vs $\mathrm{M}-\mathrm{F}$ 


\section{Dual energy X-ray absorptiometry (DXA)}

Bone mineral density (BMD) was measured at distal tibial diaphysis (TDIA), a predominantly cortical site, and distal tibial epiphysis (TEPI), an area containing a substantial amount of trabecular bone, using dual-energy X-ray absorptiometry (DXA; Hologic QDR 4500A, Hologic Inc., Bedford, Mass., USA). Bone mineral density measurement at distal tibia is a standardized method established earlier by our group [21]. Briefly, the region of interest (ROI) is defined as the area of $120 \mathrm{~mm}$ height and $129 \mathrm{~mm}$ width, starting $10 \mathrm{~mm}$ above the top of the ankle joint space. TEPI corresponds to the distal $40 \mathrm{~mm}$ of the ROI while TDIA corresponds to the proximal $40 \mathrm{~mm}$ of this ROI [21]. In addition BMD was measured at the lumbar spine (LS, second to fourth lumbar vertebra), the total hip (HIP) and the whole body (WB). For more detailed analysis of HIP the following subregions were analyzed: femoral neck (FN), intertrochanteric region (INTER), trochanter (TROC), Ward's triangle (WARD). Peripheral bone measurements were carried out at the non-dominant limb. Scan acquisition and analysis were performed using standard software procedures supplied by the manufacturer (software version 8.17).

BMD was expressed as $\mathrm{g} / \mathrm{cm}^{2}$ of hydroxyapatite and as $Z$-scores (SD from the mean of a healthy population of the same age), both, for the genetic and the phenotypic gender. A population of 400 normal Caucasian women and men, 20-80 years of age, living in the area of Berne, served as reference. Peak bone mass (mean value $\pm \mathrm{SD}$ ) derived from that female and male reference population is $1.078 \pm 0.131$, and $1.100 \pm 0.139 \mathrm{~g} / \mathrm{cm}^{2}$ at LS, $\quad 0.835 \pm 0.100$, and $0.937 \pm 0.121 \mathrm{~g} / \mathrm{cm}^{2}$ at $\mathrm{FN}$, $1.278 \pm 0.116$, and $1.375 \pm 0.118 \mathrm{~g} / \mathrm{cm}^{2}$ at TDIA, $0.763 \pm 0.094$, and $0.927 \pm 0.119 \mathrm{~g} / \mathrm{cm}^{2}$ at TEPI. Quality control by means of daily measurement of the anthropomorphic spine phantom supplied by the manufacturer revealed a precision error of $0.3 \%,(\mathrm{CV}$, coefficient of variation). The mean precision error of DXA measurements in our hands was $1.0 \%$ (LS, HIP, WB), and $1.4 \%$ (TDIA, TEPI) in vivo.

Biochemical parameters and assays (for reference ranges, see Table 5)

\section{Serum measurements}

Fasting venous blood samples were taken in the morning. Serum concentrations of total calcium (Ca total), inorganic phosphate (Pi), alkaline phosphatase activity (AP) and creatinine (Cr) were measured by autoanalyzer techniques.

Ionized calcium $\left(\mathrm{Ca}^{2+}\right)$ was measured by ion-selective electrode (Ciba-Corning Diagnostics Corp., Medfield, Mass., USA). Intact PTH (PTH), osteocalcin, (OC) and insulin-like growth factor-1 (IGF-1) were measured by two-site immunoradiometric assay (Nic- hols Institute, San Juan Capistrano, Calif., USA). 25Hydroxyvitamin $\mathrm{D}_{3}\left(25-\mathrm{OH}-\mathrm{D}_{3}\right)$ and insulin-like growth factor-binding protein-3 (IGFBP-3) were measured by competitive protein-binding RIA (Nichols).

Thyroid stimulating hormone (TSH) was measured by AxSYM Ultrasensitive II microparticle enzyme immunoassay (Abbott, Abbott Park, Ill., USA). Estradiol ( $E_{2}$; ESTR-US-CT, CIS bio international, Gif-sur-Yvette Cedex, France) and free testosterone (fT; Coat-a-Count, Diagnostic Products Corporation, Los Angeles, Calif., USA) were measured by RIA. Luteinizing hormone (LH) and follicle stimulating hormone (FSH) were measured by electrochemiluminescence immunoassay (Elecsys; Roche Diagnostics $\mathrm{GmbH}$, Mannheim, Germany). Manufacturers' reference ranges were used.

\section{Urine measurements}

Fasting 2-h urine samples were analyzed for $\mathrm{Ca}$ and $\mathrm{Cr}$ by autoanalyzer techniques. Urinary hydroxyproline (OH-Pro) was measured using a Hypronosticon kit (Organon Teknika, Boxtel, The Netherlands). Urinary $\mathrm{Ca}$ and $\mathrm{OH}-\mathrm{Pro}$ excretion were expressed as ratios to $\mathrm{Cr}$ $(\mathrm{Ca} / \mathrm{Cr}$ and $\mathrm{OH}-\mathrm{Pro} / \mathrm{Cr})$. Manufacturers' reference ranges were used.

\section{Statistics}

The studied populations showed non-normal distributions and/or unequal variances of data. A conservative data analysis approach was chosen to maximize the robustness of the statistical significances observed, eventually at the expense of an increased risk of type 2 error and a parallel loss in study power. Medians and median absolute deviations (MAD) were calculated and non-parametric tests were chosen for analysis. MannWhitney rank sum tests were performed to assess a significant median difference between M-F and F-M results. One sample sign tests were performed to test for significance between the median $Z$-scores of the study population versus normal controls of the same genetic and the same phenotypic gender, respectively. Simple regression was performed to study the influence of total treatment duration on $Z$-scores and to test for correlations between BMD $Z$-scores and LH and FSH serum values. Multiple regression analysis was performed to study the respective effects of age and total treatment duration on biochemical parameters of bone metabolism and bone mineral density. Significance levels were set using the Bonferroni correction to compensate for multiple testing.

\section{Results}

Detailed characteristics of the study population are given in Table 1. Detailed BMD results expressed as median $Z$-scores are shown in Tables 2, 3 and 4 and Fig. 1. 
Detailed results of laboratory parameters of bone turnover and sexual endocrinology are shown in Table 5.

\section{M-F transsexuals}

M-F transsexuals had a median age of 44.4 years and were treated by cross-sex hormone treatment during median 2.1 years before surgery and 9.7 years after surgery (Table 1). As compared with normal male (genetic) age-matched controls, BMD values measured at all sites were not significantly different. As compared to normal female (phenotypic) age-matched controls, BMD values at TDIA and WB showed a significantly higher median $Z$-score $(P<0.01$, Tables 2,3 and 4$)$. The detailed analysis of the HIP and its four subregions showed no significant differences in BMD values versus genotypic and phenotypic controls (Tables 2, 3 and 4). Five M-F transsexuals had osteoporosis as defined according to the WHO (Fig. 1), i.e. a $T$-score (SD from genotypic peak bone mass) below $-2.5 \mathrm{SD}$ at least at one site measured [4].

All biological parameters of bone metabolism (Table 5) were within normal range. Cross-sex hormonal treatment with estrogens was reflected by median estradiol values at the upper limit of the phenotypic normal range and within a large scatter ranging from below normal range ( $37 \mathrm{pmol} / \mathrm{l})$ to 45 times the upper limit of the normal range $(8140 \mathrm{pmol} / \mathrm{l})$. Median FSH values were elevated, corresponding to a broad range of estradiol values. $\mathrm{LH}$ and $\mathrm{FSH}$ values were significantly correlated with the BMD genotypic $Z$-scores at the LS $(r=0.51$, $P=0.014$ and $r=0.60, P=0.003$ respectively) but no correlation was found with other measurement sites.

\section{F-M transsexuals}

F-M transsexuals had a median age of 34.4 years and were treated by cross-sex hormones during median 1.3 years before surgery, which was continued for 6.1 years after surgery (Table 1). F-M transsexuals had significantly higher median $Z$-scores compared with female (genetic) age matched controls at TDIA, TEPI and WB $(+1 \pm 0.4 \mathrm{SD}, \quad+0.9 \pm 0.2 \mathrm{SD}, \quad$ and $+1.4 \pm 0.3 \mathrm{SD}$, respectively, $P<0.0001$ for all), whereas $Z$-scores at LS

Table 2 Absolute BMD values $\left(\mathrm{g} / \mathrm{cm}^{2}\right)$ at various skeletal sites of 24 male-to-female $(M-F)$ and 15 female-to-male $(F-M)$ transsexuals (median \pm MAD). $M A D$ median absolute deviation

\begin{tabular}{lll}
\hline & M-F & F-M \\
\hline Lumbar spine (LS) & $1.056 \pm 0.137$ & $1.075 \pm 0.088$ \\
Total hip (HIP) & $0.909 \pm 0.124$ & $0.970 \pm 0.071$ \\
Femoral neck (FN) & $0.774 \pm 0.095$ & $0.842 \pm 0.058$ \\
Trochanter (TROC) & $0.716 \pm 0.097$ & $0.764 \pm 0.046$ \\
Intertrochanteric region (INTER) & $1.049 \pm 0.154$ & $1.132 \pm 0.106$ \\
Ward's triangle (WARD) & $0.593 \pm 0.141$ & $0.743 \pm 0.046$ \\
Tibial diaphysis (TDIA) & $1.424 \pm 0.100$ & $1.381 \pm 0.052$ \\
Tibial epiphysis (TEPI) & $0.831 \pm 0.123$ & $0.825 \pm 0.024$ \\
Whole body (WB) & $1.216 \pm 0.098$ & $1.179 \pm 0.035$ \\
\hline
\end{tabular}

Table 3 BMD $Z$-scores at various skeletal sites of 24 male-tofemale $(M-F)$ and 15 female-to-male $(F-M)$ transsexuals (median \pm MAD). $Z$-score vs genotypic controls ${ }^{\mathrm{a}}$. $M A D$ median absolute deviation

\begin{tabular}{lrl}
\hline & \multicolumn{1}{l}{ M-F } & F-M \\
\hline Lumbar spine (LS) & $0.2 \pm 0.9$ & $0.4 \pm 0.7$ \\
Total hip (HIP) & $-0.5 \pm 0.9$ & $0.4 \pm 0.5$ \\
Femoral neck (FN) & $-0.2 \pm 1.0$ & $0.3 \pm 0.5$ \\
Trochanter (TROC) & $-0.3 \pm 0.8$ & $1.0 \pm 0.6$ \\
Intertrochanteric region (INTER) & $-0.6 \pm 0.8$ & $0.3 \pm 0.6$ \\
Ward's triangle (WARD) & $-0.1 \pm 0.7$ & $0.3 \pm 0.6$ \\
Tibial diaphysis (TDIA) & $0.6 \pm 0.8$ & $1.0 \pm 0.4^{* *}$ \\
Tibial epiphysis (TEPI) & $-0.3 \pm 0.9$ & $0.9 \pm 0.2^{* *}$ \\
Whole body (WB) & $1.1 \pm 1.1$ & $1.4 \pm 0.3^{* *}$ \\
\hline
\end{tabular}

${ }^{\mathbf{a}}$ vs normal controls of the same genetic gender (M-F vs M and F-M vs F)

$* * P<0.0001$ vs age-matched normal controls

Table 4 BMD $Z$-scores at various skeletal sites of 24 male-tofemale $(M-F)$ and 15 female-to-male $(F-M)$ transsexuals (median \pm MAD). $Z$-score vs phenotypic controls ${ }^{\mathrm{a}}$. $M A D$ median absolute deviation

\begin{tabular}{llr}
\hline & M-F & \multicolumn{1}{l}{ F-M } \\
\hline Lumbar spine (LS) & $0.4 \pm 0.9$ & $0.3 \pm 0.7$ \\
Total hip (HIP) & $0.3 \pm 1.2$ & $-0.3 \pm 0.5$ \\
Femoral neck (FN) & $0.2 \pm 1.2$ & $-0.1 \pm 0.5$ \\
Trochanter (TROC) & $0.3 \pm 1.3$ & $0.2 \pm 0.6$ \\
Intertrochanteric region (INTER) & $0.1 \pm 1.0$ & $-0.2 \pm 0.5$ \\
Ward's triangle (WARD) & $0.2 \pm 0.9$ & $0.1 \pm 0.5$ \\
Tibial diaphysis (TDIA) & $1.7 \pm 1.0^{*}$ & $0.1 \pm 0.4$ \\
Tibial epiphysis (TEPI) & $1.3 \pm 1.4$ & $-0.6 \pm 0.3^{*}$ \\
Whole body (WB) & $1.8 \pm 1.1^{*}$ & $0.7 \pm 0.4$ \\
\hline
\end{tabular}

${ }^{\mathrm{a}} \mathrm{vs}$ normal controls of the same phenotypic gender (M-F vs F and F-M vs M)

$* P<0.01$ vs age-matched normal controls

and HIP, including the hip subregions were not significantly different. As compared to normal male (phenotypic) age-matched controls, $Z$-scores were not significantly different, except for lower values at TEPI $(-0.6 \pm 0.4 \mathrm{SD}, P<0.01$, Tables 2,3 and 4$)$.

All biological parameters of bone metabolism were within normal range (Table 5). Cross-sex hormonal treatment with androgens was reflected by elevated median testosterone values for women but within the normal range for men, the scatter ranging from low values of $2 \mathrm{pmol} / 1$ to values at 1.5 times the upper limit for normal men (194 pmol/1). Median FSH values were elevated, corresponding to the broad range of testosterone values. LH and FSH values did not correlate either with the BMD genotypic $Z$-scores at the LS ( $r=0.04, P=0.87$, and $r=0.1, P=0.73$, respectively) or at any other measurement site.

\section{Comparison between M-F and F-M transsexuals}

In this study, M-F transsexuals were significantly older, taller, heavier and had a significantly longer duration of 

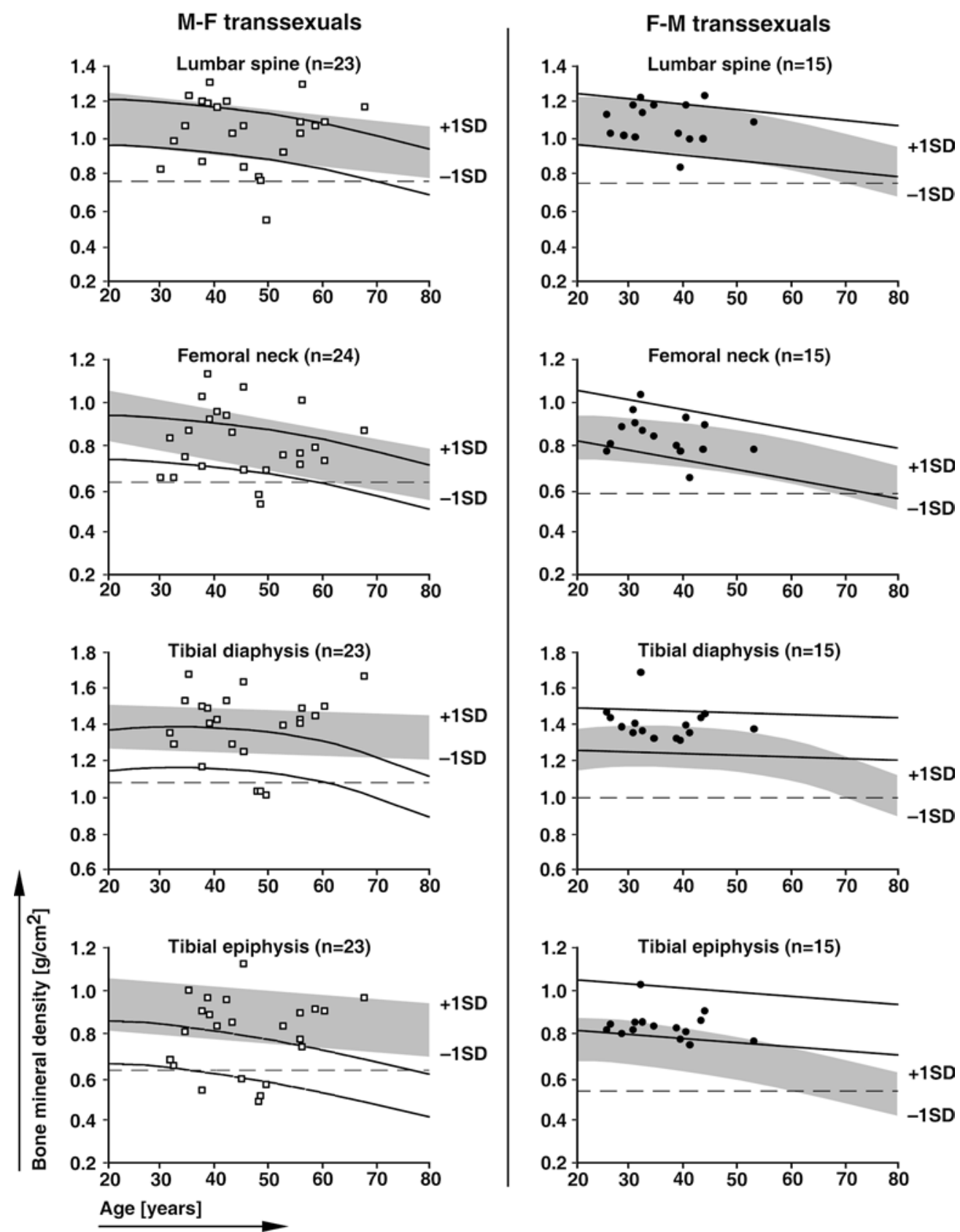

Fig. 1 Individual BMD values at peripheral and central measurement sites compared to mean \pm 1 SD values for normal genotypic controls (male for M-F transsexuals and female for F-M transsexuals, shaded area) and normal phenotypic controls (female for M-F transsexuals and male for F-M transsexuals, area between the lines). The dotted line represents the cut-off value of $T$-score $-2.5 \mathrm{SD}$

pre-surgery cross-sex hormonal treatment than F-M transsexuals (Table 1). They showed larger interindividual variability in $Z$-scores than F-M transsexuals; however, the differences in BMD between M-F and F-M transsexuals were not significant at any site measured (all $P>0.25$, Tables 2, 3 and 4). Total duration of crosssex hormone treatment influenced the $Z$-score of tibial diaphysis in M-F transsexuals only: each treatment year

caused a decrease by $0.1 \mathrm{SD}\left(r^{2}=0.19, P=0.04\right)$. At other measurement sites, no similar influence was detected.

F-M transsexuals had significantly higher IGF-1 and testosterone levels $(P<0.001)$, as compared to M-F transsexuals. All other parameters of bone metabolism were not significantly different between F-M and M-F transsexuals and within normal ranges.

\section{Discussion}

This study explores the effect of long-term cross-sex hormonal treatment in male-to-female (M-F) and female-to-male (F-M) transsexuals on the bone mineral 
Table 5 Parameters of bone metabolism in serum and urine of 24 male-to-female $(M-F)$ and 15 female-to-male $(F-M)$ transsexuals. Results given as median \pm MAD (range). Normal range of males and females. $C a$ calcium, $P h$ phosphate, $C r$ creatinine, $A P$ alkaline phosphatase, IGFBP-3 insulin-like growth factor-binding protein3, $E_{2} 17 \beta$-estradiol, $O H$-Pro hydroxyproline

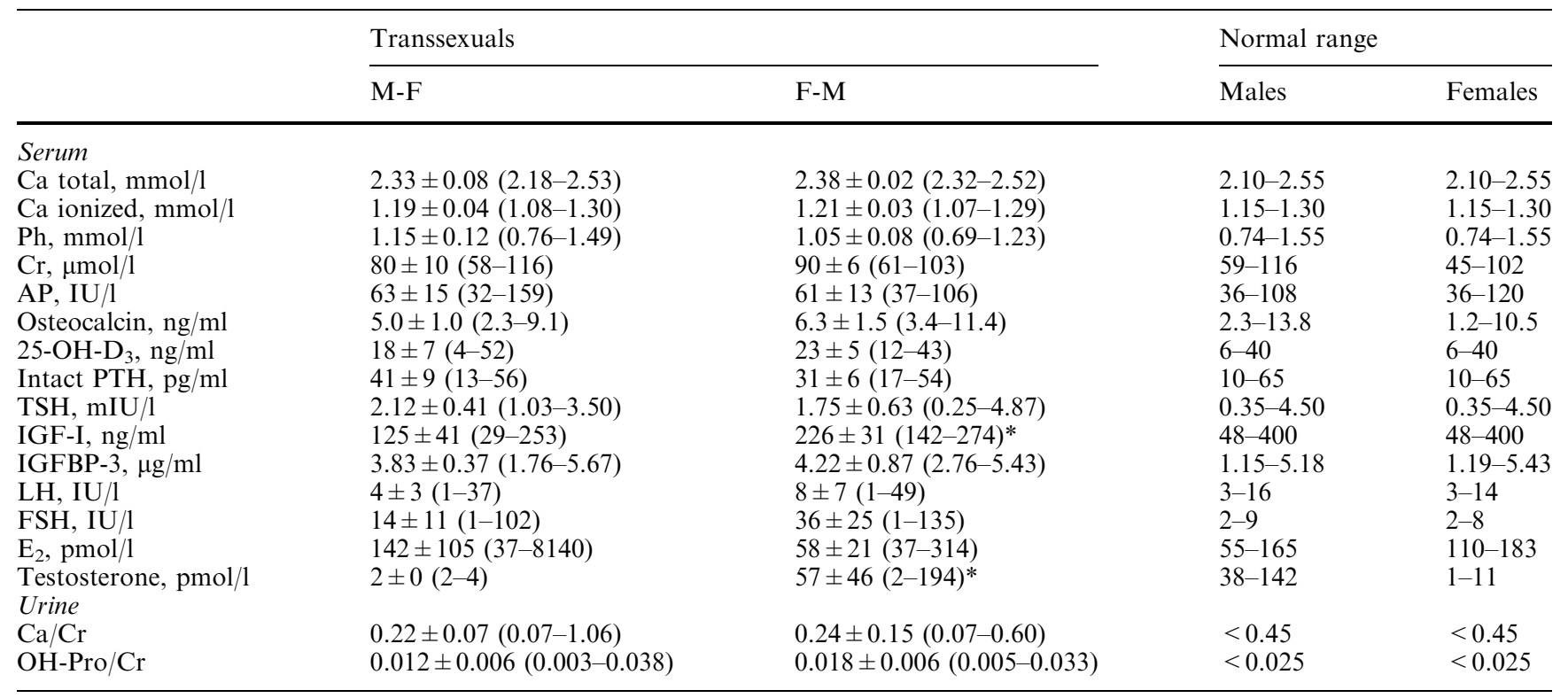

Significance by Wilcoxon rank sum test: $* P<0.001$, F-M vs M-F

density of sites with substantial amount of cortical bone (TDIA and WB), sites with predominantly trabecular bone (TEPI, TROC, WARD, LS) and sites with balanced repartition of cortical and trabecular bone (INTER, FN), as well as on markers of bone metabolism.

The M-F/F-M ratio of transsexuals controlled in the outpatient department of gynecologic endocrinology and reproductive medicine of the University Hospital of Berne is approximately $3: 2$. A corresponding ratio of almost 3:1 has been reported earlier, considering $95 \%$ of the Dutch population of transsexuals [16].

Usually, male BMD values exceed those of females, as indicated by our reference ranges. Whereas in peripheral bones, such as the tibia, those gender differences are larger, they tend to be smaller at the hip and almost negligible at the lumbar spine. Similar findings were published earlier [22,23].

\section{F-M transsexuals}

Due to the cross-sectional design of this study, the observed effects of androgens on bone in F-M transsexuals could be simply due to a selection bias, e.g. by assuming that women undergoing sex reassignment would be taller or heavier than average women in Switzerland. Based on the most recent data of the Swiss Federal Office for Statistics in 1997 (mean \pm SD), the average height and weight for Swiss women aged 25-34 and 35-44 years is $165.7 \pm 6.2$ and $164.4 \pm 6.3 \mathrm{~cm}$, respectively, and $58.7 \pm 9.4$ and $60.3 \pm 9.7 \mathrm{~kg}$, respectively (personal communication from Dr. Wüest, Bundesamt für Statistik, Bern, Switzerland). At a median age of $35 \pm 4.5$ years, the women included in our normative database for BMD measurements had a median height of $165 \pm 4 \mathrm{~cm}$ and a median weight of $59 \pm 5 \mathrm{~kg}$. These data compare well with the calculated medians \pm MAD of F-M transsexuals in this study: $166.0 \pm 3.0 \mathrm{~cm}$ and $60.2 \pm 8.0 \mathrm{~kg}$ at a median age of $34.4 \pm 5.6$ years.

Androgens have been shown to promote bone growth and by the end of puberty, men have greater bone mass and greater cortical diameter than women $[24,25,26,27,28]$. In addition, it has been observed that long bone dimensions continue to increase during adulthood in men, presumably in relationship with periosteal bone apposition [29]. In the present study and in contrast, no significant correlation was found between age or duration of cross-sex hormone treatment and bone area measured at any site (data not shown). In this cross-sectional study, F-M transsexuals under cross-sex hormone treatment had higher bone density values than women at tibia and WB. The magnitude of this increased BMD was such that they compared favorably with men, with the exception of TEPI. These observations are in favor of a cortical effect of androgen treatment in F-M transsexuals. However, these potential androgenic effects on cortical bone were not found at the HIP and its different subregions or at the LS, possibly in relation with the increasing proportion of trabecular bone. Androgens may exert an inhibitory effect on bone resorption [30] as well as a stimulation of bone formation [31] via cytokines and IGF-1. IGF-1 has been shown to have potent actions on bone and its serum levels are increased by androgens [32]. In addition in the present study, F-M transsexuals had significantly higher serum IGF-1 levels than M-F transsexuals, which may 
be the result of the androgen therapy and explain, at least in part, the gain in cortical bone observed at the tibia and the whole body. The correlation of IGF-1 levels with BMD values in men and women has been shown in some publications [33,34], while other publications reported the absence of correlation [35] or a correlation in men only [36]. In the present study with M-F and F-M transsexuals, no correlation could be established between BMD values, IGF-1 values and serum testosterone levels.

\section{M-F transsexuals}

M-F transsexuals were treated with an antiandrogen and estrogens. The estrogen dosage used after surgery was generally higher than the one used in genetic women suffering from early menopause. The BMD results suggest preservation at all sites over a median duration of cross-sex hormone treatment of 12.5 years, with BMD results not significantly different from the genetic (male) reference range. Furthermore, BMD $Z$-scores at the tibial diaphysis and the whole body, both representing mainly cortical bone, were significantly higher in M-F transsexuals than in normal women, indicating that the higher peak bone mass acquired during puberty $[24,28]$ was maintained by estrogens despite anti-androgen treatment. Serum FSH and LH values were significantly correlated with $Z$-scores measured at the lumbar spine. This finding reinforces the importance of these two biochemical parameters as potential surrogates representing the outcome of successful sex hormone replacement therapy in M-F transsexuals [15]. The IGF-1 values were significantly lower than in F-M transsexuals treated with androgens, remained however within the normal range. In a cross-sectional study in M-F transsexuals, potential suppression of bone resorption after cross-sex hormonal treatment of 24 months median without associated bone loss as assessed by histomorphometry and biochemical parameters was reported by Lips et al. [12]. Decreased bone turnover and IGF-1 levels with subsequent increase in lumbar spine BMD were documented by the same group after one year of cross-sex hormonal treatment in M-F transsexuals [14]. A long-term follow-up over 32-63 months of cross-sex hormonal treatment confirmed a continuing decrease of bone turnover, but failed to confirm the significant increase in lumbar spine BMD observed in the first year [15]. Goh et al. demonstrated that Singaporean ovariectomized F-M transsexuals had a significantly higher lumbar spine BMD after 1-3 years of androgen treatment than age-matched female controls and that lumbar spine BMD increased if androgens were resumed in those genetically female individuals who had stopped hormonal substitution [11]. Vered et al. demonstrated increased lumbar spine and femoral neck BMD in a 39year-old XY female with complete androgen insensitivity after treatment with conjugated estrogens for 4 years and in a 37-year-old XX male with $11 \beta$-hydroxylase deficiency treated with testosterone for 27 months. The authors concluded that phenotypically matched sex hormone therapy was essential not only to maintain external appearance, but also for the preservation of bone mass [37].

In the present study, large interindividual variations in bone mineral density were observed in M-F transsexuals: five subjects had a BMD genotypic $T$-score below $-2.5 \mathrm{SD}$ at least at one site of measurement and therefore had osteoporosis according to the WHO definition. All five patients had low estradiol levels and elevated FSH values, indicating that compliance with their treatment with sex hormones was inappropriate. Another finding was that a limited number of M-F transsexuals were taking more estrogens than needed for preservation of bone. Although their FSH levels were almost totally suppressed and their estradiol levels as high as 35 times the upper limit of the normal range, their IGF-1 and BMD values were within normal range.

Our study has several limitations. It was a cross-sectional observational study. However, the subjects were all treated with the same cross-sex hormone treatment regimen and followed over up to 24 years after sex reassignment surgery. This study was explorative by nature and one of its goals was to generate hypotheses for prospective longitudinal trials. The data analysis strategy was defined in order to maximize the robustness of the statistical significances observed (Bonferroni correction, use of non-parametric statistical tests), which occurred at the expense of an increased risk of type two error and a parallel loss in study power. We may therefore have missed some statistically significant correlations or differences between groups. However, and considering the difficulties in realizing a prospective trial with transsexuals to test newly generated hypotheses, the conservative analysis of the present data would be expected to maximize the chances to confirm these findings.

The increased BMD observed at the tibia in F-M transsexuals with long term cross-sex hormonal treatment with testosterone might have been influenced by testosterone-induced modifications in bone size [27]. The number of included patients was too small to identify significant changes in bone area with age or duration of cross-sex hormone treatment at any site. Another appealing approach would have been the calculation of volumetric BMD based on simple models of bone shape [38], which could have brought interesting new insights if more consistent data on bone area would have been available. In addition, this study was not designed to systematically record lifestyle parameters, which may influence BMD or biochemical parameters of bone metabolism (e.g. physical activity level, alcohol consumption, smoking etc.), which might have acted as possible confounders. However, all biochemical values of calcium phosphate metabolism parameters were within normal ranges and comparable across groups.

In transsexual genetic males and females under long term cross-sex hormone treatment, BMD values are generally preserved or increased. Non-compliance with 
cross-sex hormone treatment may lead to low BMD, which in this study was observed only in genetic males. IGF-1 could play a role in the mediation of the effect of androgens on bone in F-M transsexuals.

Acknowledgements We thank Dr. Philippe Kress for his invaluable contribution to the preparation of the manuscript.

\section{References}

1. Holmes SJ, Shalet SM (1996) Role of growth hormone and sex steroids in achieving and maintaining normal bone mass. Horm Res 45:86-93

2. Delmas PD (1997) Hormone replacement therapy in the prevention and treatment of osteoporosis. Osteoporos Int $7 \mathrm{Suppl}$ $1: \mathrm{S} 3-7$

3. Saggese G, Bertelloni S, Baroncelli GI (1997) Sex steroids and the acquisition of bone mass. Horm Res 48 Suppl 5:65-71

4. (1997) Consensus development statement on osteoporosis: who are candidates for prevention and treatment of osteoporosis. Osteoporos Int 7:1-6

5. Riggs BL, Khosla S, Melton LJ 3rd (1998) A unitary model for involutional osteoporosis: estrogen deficiency causes both type I and type II osteoporosis in postmenopausal women and contributes to bone loss in aging men. J Bone Miner Res 13:763-773

6. Gibaldi M (1997) Prevention and treatment of osteoporosis: does the future belong to hormone replacement therapy? J Clin Pharmacol 37:1087-1099

7. Rozenberg S, Vandromme J, Kroll M, Pastijn A, Degueldre M (1994) Osteoporosis prevention with sex hormone replacement therapy. Int J Fertil Menopausal Stud 39:262-271

8. Swerdloff RS, Wang C (1993) Androgens and aging in men. Exp Gerontol 28:435-446

9. Winters SJ (1999) Current status of testosterone replacement therapy in men. Arch Fam Med 8:257-263

10. Hansen KA, Tho SP (1998) Androgens and bone health. Semin Reprod Endocrinol 16:129-134

11. Goh HH, Ratnam SS (1997) Effects of hormone deficiency, androgen therapy and calcium supplementation on bone mineral density in female transsexuals. Maturitas 26:45-52

12. Lips $P$, Asscheman H, Uitewaal P, Netelenbos JC, Gooren L (1989) The effect of cross-gender hormonal treatment on bone metabolism in male-to-female transsexuals. J Bone Miner Res 4:657-662

13. Lips P, van Kesteren PJ, Asscheman H, Gooren LJ (1996) The effect of androgen treatment on bone metabolism in female-tomale transsexuals. J Bone Miner Res 11:1769-1773

14. van Kesteren P, Lips P, Deville W, Popp-Snijders C, Asscheman H, Megens J, Gooren L (1996) The effect of one-year cross-sex hormonal treatment on bone metabolism and serum insulin-like growth factor-1 in transsexuals. J Clin Endocrinol Metab 81:2227-2232

15. van Kesteren P, Lips P, Gooren LJ, Asscheman H, Megens J (1998) Long-term follow-up of bone mineral density and bone metabolism in transsexuals treated with cross-sex hormones. Clin Endocrinol (Oxf) 48:347-354

16. van Kesteren PJ, Asscheman H, Megens JA, Gooren LJ (1997) Mortality and morbidity in transsexual subjects treated with cross-sex hormones. Clin Endocrinol (Oxf) 47:337-342

17. Colvard D, Spelsberg T, Eriksen E, Keeting P, Riggs BL (1989) Evidence of steroid receptors in human osteoblast-like cells. Connect Tissue Res 20:33-40

18. Vanderschueren D, Vandenput L, Boonen S, Lindberg MK, Bouillon R, Ohlsson C (2004) Androgens and bone. Endocr Rev 25:389-425

19. Wiren KM, Chapman Evans A, Zhang XW (2002) Osteoblast differentiation influences androgen and estrogen receptor-alpha and -beta expression. J Endocrinol 175:683-694
20. Schlatterer K, Yassouridis A, von Werder K, Poland D, Kemper J, Stalla GK (1998) A follow-up study for estimatingthe effectiveness of a cross-gender hormone substitution therapy on transsexual patients. Arch Sex Behav 27:475492

21. Casez JP, Troendle A, Lippuner K, Jaeger P (1994) Bone mineral density at distal tibia using dual-energy X-ray absorptiometry in normal women and in patients with vertebral osteoporosis or primary hyperparathyroidism. J Bone Miner Res 9:1851-1857

22. Duncan EL, Cardon LR, Sinsheimer JS, Wass JA, Brown MA (2003) Site and gender specificity of inheritance of bone mineral density. J Bone Miner Res 18:1531-1538

23. Rubin K, Schirduan V, Gendreau P, Sarfarazi M, Mendola R, Dalsky G (1993) Predictors of axial and peripheral bone mineral density in healthy children and adolescents, with special attention to the role of puberty. J Pediatr 123:863-870

24. Bonjour JP, Theintz G, Law F, Slosman D, Rizzoli R (1994) Peak bone mass. Osteoporos Int 4 Suppl 1:7-13

25. Martin B (1993) Aging and strength of bone as a structural material. Calcif Tissue Int 53 Suppl 1:S34-39; discussion S3940

26. Seeman E (2002) Pathogenesis of bone fragility in women and men. Lancet 359:1841-1850

27. Seeman E (2003) The structural and biomechanical basis of the gain and loss of bone strength in women and men. Endocrinol Metab Clin N Am 32:25-38

28. van der Meulen MC, Ashford MW Jr, Kiratli BJ, Bachrach LK, Carter DR (1996) Determinants of femoral geometry and structure during adolescent growth. J Orthop Res 14:22-29

29. Ruff CB, Hayes WC (1988) Sex differences in age-related remodeling of the femur and tibia. J Orthop Res 6:886-896

30. Bellido T, Jilka RL, Boyce BF, Girasole G, Broxmeyer H, Dalrymple SA, Murray R, Manolagas SC (1995) Regulation of interleukin-6, osteoclastogenesis, and bone mass by androgens. The role of the androgen receptor. J Clin Invest 95:2886-2895

31. Orwoll ES, Bauer DC, Vogt TM, Fox KM (1996) Axial bone mass in older women. Study of Osteoporotic Fractures Research Group. Ann Int Med 124:187-196

32. Mauras N, Blizzard RM, Link K, Johnson ML, Rogol AD, Veldhuis JD (1987) Augmentation of growth hormone secretion during puberty: evidence for a pulse amplitude-modulated phenomenon. J Clin Endocrinol Metab 64:596-601

33. Gillberg P, Olofsson H, Mallmin H, Blum WF, Ljunghall S, Nilsson AG (2002) Bone mineral density in femoral neck is positively correlated to circulating insulin-like growth factor (IGF)-I and IGF-binding protein (IGFBP)-3 in Swedish men. Calcif Tissue Int 70:22-29

34. Vestergaard P, Hermann AP, Orskov H, Mosekilde L (1999) Effect of sex hormone replacement on the insulin-like growth factor system and bone mineral: a cross-sectional and longitudinal study in 595 perimenopausal women participating in the Danish Osteoporosis Prevention Study. J Clin Endocrinol Metab 84:2286-2290

35. Collins D, Woods A, Herd R, Blake G, Fogelman I, Wheeler M, Swaminathan R (1998) Insulin-like growth factor-I and bone mineral density. Bone 23:13-16

36. Karasik D, Rosen CJ, Hannan MT, Broe KE, Dawson-Hughes B, Gagnon DR, Wilson PW, Visser M, Langlois JA, Mohan S, Kiel DP (2002) Insulin-like growth factor binding proteins 4 and 5 and bone mineral density in elderly men and women. Calcif Tissue Int 71:323-328

37. Vered I, Kaiserman I, Sela BA, Sack J (1997) Cross genotype sex hormone treatment in two cases of hypogonadal osteoporosis. J Clin Endocrinol Metab 82:576-578

38. Gravholt $\mathrm{CH}$, Lauridsen AL, Brixen K, Mosekilde L, Heickendorff L, Christiansen JS (2002) Marked disproportionality in bone size and mineral, and distinct abnormalities in bone markers and calcitropic hormones in adult turner syndrome: a cross-sectional study. J Clin Endocrinol Metab 87:2798-2808 